\title{
Chapter 8: A Laboratory Experiment for the Estimation of Health Risks: Policy Recommendations.
}

\author{
${ }^{1}$ Drichoutis, A., ${ }^{2}$ Koundouri, P., ${ }^{3}$ Remoundou, K., \\ ${ }^{1}$ University of Ioannina, GREECE. \\ ${ }^{2}$ Athens University of Economics and Business, GREECE \\ ${ }^{3}$ Aberystwyth University, $U K$
}

Environmental health hazards in Asopos River Basin (RB) rise concerns on health risk not only for the residents of the catchment but also for the consumers of the area's products across the country. As a result, the focus of this chapter is on the estimation of theses health risks. In order to assess the social cost from consuming products produced in an area where water resources are not in good condition a lab experimental auction has been conducted. According to the details of the experiment presented at the beginning of the chapter all participants were asked to bid to exchange a product from region A (the polluted one) with a similar product from a region in a good ecological status (in the terminology of the European Water Framework Directive (WFD)), region B. After the presentation of the employed methodology econometric analysis was conducted. The output of this analysis is an average Willingness-to-Pay (WTP) for the specific sample of consumers. WTP represents the maximum amount of money a person would be willing to pay in order to receive a good or avoid an undesired impact. The chapter concludes with policy recommendations and suggests that unless an epidemiology study confirms the health hazards from consuming agricultural products cultivated in the area of Asopos (area similar to the characteristics of region A), the estimated amount is a net cost suffered by the local farmers and compensation measures have to be adopted. 


\section{Introduction}

As presented in detail in Chapter 1 of the book, the European Water Framework Directive (WFD) (2000/60/EC) (CEC, 2000) is one of the first European Directives to recognize explicitly a role for economics in reaching environmental and ecological objectives. More specifically, the Directive calls for the application of economic principles, economic methods and instruments for achieving good water status for all EU waters in the most effective manner. The most important economic concept that the Directive introduces, is that of water resources management based on the recovery of the total economic cost of water services including the financial cost of water provision as well as the environmental and resource costs. The environmental cost reflects the welfare losses associated with water quality deterioration and the subsequent decrease in water body's capacity to sustain goods and services that are of value to people. However, since many of the services associated with water resources are not marketed, the estimation of the environmental cost is not straightforward. Health risks are an important component of the environmental cost associated with degradation in water quality. Epidemiological studies have found significant morbidity being associated with consumption of products being cultivated with contaminated water. Yet, health risks are often neglected in policy making due to the inherent difficulties in monetizing them.

In this chapter we employ an experimental auction in the laboratory to elicit participants WTP to hedge against health risks associated with consumption of agricultural products cultivated in the Asopos RB. Experimental auctions offer an alternative to stated preference techniques, implemented in Chapter 6, in eliciting preferences and values. Moreover, since subjects are offered real incentives, values are potentially free of hypothetical biases that welfare measures under hypothetical surveys are often criticized for. Health risks due to the use of contaminated water in agriculture are a significant concern in the Asopos RB. 
Although epidemiological studies relating the degree of pollution with health risks are not available in the area, toxicological surveys have shown that heavy metals concentrations in the groundwater, mainly hexavalent chromium - Cr(VI), are above the safety levels. This presents a potential risk for the health of the people consuming products from the area and subsequently entails a financial cost for the farmers due to difficulties in marketing their products. Therefore results from this experiment aim to feedback in the design of appropriate economic measures to internalize this externality according to the polluter pays principle that the Directive introduces.

\section{Review of the literature}

Reflecting greater awareness for environmental and health issues in recent years, a vast literature eliciting valuations for food safety has emerged. The majority of studies use stated preference techniques to elicit people's preferences and WTP premiums for food products that are of certified quality. Genetically modified products and pesticides residues are among the food hazards that have been more extensively studied. The literature in general finds that people are WTP significant amounts to protect themselves from health hazards associated with food consumption. Another common finding is that consumers tend to overestimate low probabilities of risks associated with food safety due to negative publicity and incomplete information (Aldrich, 1994). Morkbak et al. (2008) present an overview of the existing studies on the valuation of food safety and quality in meat. In a meta-analysis of studies eliciting preferences toward pesticides-related health risks, Florax et al. (2005) find that people hold significant values for pesticide risk mitigation which are responsive to the proposed risk reduction. There is also a large literature on consumer preferences for genetically modified food. Costa-font et al. (2008) and Lusk et al. (2005) summarize the existing evidence and conclude that in general a high premium for non-GM food is reported in the literature. 
Groundwater contamination has not extensively been studied in relation to food safety. Among the exceptions, Stenger (2000) elicit WTP in an experimental setting for protection against heavy metal (cadmium) contamination. Authors stress the importance to account for subjective risk perceptions in the valuation process. In a similar study, Rozan et al. (2004) employ an experimental auction to assess consumers WTP to avoid health risks from heavy metal content in food. Authors find significant premiums that are sensitive to the provided information about food safety.

Drawing on this literature, we examine in this chapter whether consumers are WTP a premium to avoid potential health risks related to heavy metal contamination of the agricultural products. To this end, we designed an experiment where participants had the opportunity to exchange an agricultural endowment from a river basin not in good ecological status according to the terminology of the WFD with a similar endowment from a different region. The experimental setting involved participants bidding in a fourth price Vickrey auction. We are further interested in investigating whether valuation changes when information on the higher health risk to which children are exposed, given their longer time span, is provided. We thus follow a split sample approach with half of our sample being exposed to the additional information. Furthermore we investigate how risk perception influences individual valuations of exposure risk reductions.

\section{Experimental design}

\subsection{Subjects}

We recruited a sample of consumers from the population of Athens. Recruitment was undertaken by a professional research company. Subjects were told that they would participate in an experiment for a compensation of 20 euros for their participation with the understanding that the final amount may vary given decisions during the experiment. The 
nature of the experiment was not revealed to avoid self selection. The experiments took place at the laboratory of the Agricultural University of Athens, lasted for about one hour and one of the authors served as the experimenter in all sessions. We conducted four sessions with a total of 61 consumers. Table 1 describes the experimental design.

Table 1: Experimental design

\begin{tabular}{|c|c|c|c|}
\hline Treatments & $\begin{array}{l}\text { Subject pool } \\
\text { (N) }\end{array}$ & Information on health risk & $\begin{array}{l}\text { Warm glow } \\
\text { isolated }^{1}\end{array}$ \\
\hline 1 & 15 & General population & Yes \\
\hline 2 & 16 & General population & No \\
\hline 3 & 14 & $\begin{array}{l}\text { General population and children in } \\
\text { specific }\end{array}$ & Yes \\
\hline 4 & 16 & $\begin{array}{l}\text { General population and children in } \\
\text { specific }\end{array}$ & No \\
\hline
\end{tabular}

\subsection{Procedures and agricultural products}

For each session a training phase aiming to familiarize respondents with the auction procedures preceded the real auction. Training involved respondents bidding in three hypothetical auction rounds for a bag of potato chips and in three real auction rounds for a chocolate bar. In all sessions a $4^{\text {th }}$ price Vikrey auction was employed. Vickrey auctions are known to be demand revealing in the sense that bidding the true WTP is a dominant strategy (Lusk and Shogren, 2007). In the $4^{\text {th }}$ price auction respondents first submit their bids, bids are then ranked and the fourth higher bid is identified. All respondents having submitted bids higher than the $4^{\text {th }}$ highest bid win the auction and buy the product in the fourth highest price. In our auction subjects are first endowed with one kilo of potatoes from what we named river basin A which is in bad ecological status, bearing the same characteristics regarding heavy

\footnotetext{
${ }^{1}$ In two of the sessions, subjects were additionally informed that revenues from higher bidders would be donated in a charity of their choice on their behalf. The design of these sessions aimed to isolate warm glow incentives behind donations. Results from this analysis are reported elsewhere.
} 
metals contamination as the Asopos basin. They then bid to upgrade to one kilo of potatoes from what we named river basin B. Basin B was claimed to be certified for being in a good ecological status and therefore consumption of products from this area does not involve any health risks. We did not reveal the region of origin of potatoes to avoid any affiliation effects that could potentially bias our estimates. A leaflet was distributed describing the environmental conditions in the areas A and B. The exact text is provided in the Appendix I. Subjects participated in five auction rounds and were told that at the end one round would be randomly chosen as binding. In a final stage respondents were asked on their socioeconomics characteristics (age, household size, gender, education, income and whether they have underage children or not) as well as their perceptions of health risks from consumption of products from river basin $\mathrm{A}$ and $\mathrm{B}$. Table 2 summarizes the socioeconomic profile of the participants.

Table 2: Socio-demographic information

\begin{tabular}{|c|c|c|}
\hline Variable & Variable description & $\begin{array}{l}\text { Mean } \\
\text { (SD) }\end{array}$ \\
\hline Bid & Bid to exchange product & $\begin{array}{c}0.604 \\
(0.589)\end{array}$ \\
\hline Charity & $\begin{array}{l}\text { Dummy, } 1=\text { Subject participated in the } \\
\text { charitable auction }\end{array}$ & $\begin{array}{c}0.458 \\
(0.502)\end{array}$ \\
\hline HealthRisk & $\begin{array}{l}\text { Dummy, } 1=\text { Subject received additional } \\
\text { health risk information regarding children }\end{array}$ & $\begin{array}{c}0.492 \\
(0.504)\end{array}$ \\
\hline Age & Subject's age & $\begin{array}{l}41.508 \\
(9.839)\end{array}$ \\
\hline Gender & $=$ male & $\begin{array}{c}0.305 \\
(0.464)\end{array}$ \\
\hline Income & $\begin{array}{l}\text { Dummy, 1=Subject's household economic } \\
\text { position is above average }\end{array}$ & $\begin{array}{c}0.475 \\
(0.504)\end{array}$ \\
\hline Kids & $\begin{array}{l}\text { Dummy, } 1=\text { Subject has kids under } 18 \text { years } \\
\text { old }\end{array}$ & $\begin{array}{c}0.339 \\
(0.477)\end{array}$ \\
\hline Educ & $\begin{array}{l}\text { Dummy, } 1=\text { Subject has a university diploma } \\
\text { ( for the consumers subject pool) }\end{array}$ & $\begin{array}{c}0.610 \\
(0.492)\end{array}$ \\
\hline $\begin{array}{l}\text { PotatoConsu } \\
\text { mption }_{1}\end{array}$ & $\begin{array}{l}\text { Dummy, } 1=\text { Subject consumes potatoes } 1-2 \\
\text { times/month or less }\end{array}$ & $\begin{array}{c}0.153 \\
(0.363)\end{array}$ \\
\hline $\begin{array}{l}\text { PotatoConsu } \\
\text { mption }_{2}\end{array}$ & $\begin{array}{l}\text { Dummy, } 1=\text { Subject consumes potatoes } 1 \\
\text { time/week }\end{array}$ & $\begin{array}{c}0.186 \\
(0.393)\end{array}$ \\
\hline
\end{tabular}


PotatoConsu Dummy, 1=Subject consumes potatoes 2-3 0.441

mption $_{3} \quad$ times/week $\quad(0.501)$

PotatoConsu Dummy, 1=Subject consumes potatoes 4-5 0.220

mption $_{4} \quad$ times/week or more often $\quad(0.418)$

\section{Results}

\subsection{Risk perceptions}

A large literature in sociology suggests that risk perceptions influence consumer behavior in many different health and food safety contexts and stresses the need to account for perceptions in risk assessment and risk communication (Slovic, 1987; Frewer et al., 1998). Our risk perception variables come from replies in the following statements asking people to declare their degree of agreement in a seven point Likert scale:

I perceive consumption of agricultural products from region $A$ as being dangerous for my health'

I perceive consumption of agricultural products from region B not being dangerous for my health'

Replies were then dummy-coded for the subsequent analysis with one corresponding to agreement (declaring higher than 5 in the original scale) and 0 otherwise. Table 3 shows the mean scores. Results suggest that $86 \%$ of the respondents perceive significant risks to be entailed in consumption of agricultural products from area A that bears similar characteristics to the Asopos RB. This was true although significant effort had been placed to accurately present the scientific information available on the ecological status and pollution loads in the basin. In particular respondents were reminded the lack of epidemiological data that could establish causality between food consumption from the area and health symptoms. Accordingly, consumption of products from region $\mathrm{B}$ is considered safe from the overwhelming majority. To examine the degree to which risk perceptions can influence real 
behavior we introduce the risk variables in the regression analysis. Results can have useful implications for risk communication and can feedback in the developing awareness raising material.

Table 3: Risk perceptions

\begin{tabular}{|c|c|c|}
\hline Variable & Variable description & $\begin{array}{l}\text { Mean } \\
\text { (SD) }\end{array}$ \\
\hline DangerA & $\begin{array}{l}\text { Dummy, } 1=\text { Subject perceives consumption of } \\
\text { agricultural products from region } A \text { as being } \\
\text { dangerous to her health }\end{array}$ & $\begin{array}{c}0.864 \\
(0.345)\end{array}$ \\
\hline $\begin{array}{l}\text { NotDanger } \\
B\end{array}$ & $\begin{array}{l}\text { Dummy, } 1=\text { Subject perceives consumption of } \\
\text { agricultural products from region } B \text { not being } \\
\text { dangerous to her health }\end{array}$ & $\begin{array}{c}0.830 \\
(0.378)\end{array}$ \\
\hline
\end{tabular}

\subsection{Econometric results}

To account for the panel nature of our data, we estimated a random effects regression model. The bid function is specified as a function of the socioeconomic characteristics of the respondents, the initial monetary endowment, risk perceptions and potato consumption habits. We further control for the auction round to account for potential learning effects. The regression function is thus specified as:

Bid $_{i t}=\left(\begin{array}{l}b_{0}+b_{1} \text { Charity }_{i t}+b_{2} \text { HealthRisk }_{i t}+b_{3} \text { TotFee }_{i t}+b_{4} T_{2, i t}+b_{5} T_{3, i t}+b_{6} T_{4, i t}+b_{7} T_{5, i t} \\ +b_{8} \text { Age }_{i t}+b_{9} \text { Fender }_{i t}+b_{10} \text { Income }_{2, i t}+b_{11} \text { Kids }_{i t}+b_{12} \text { Educ }_{2, i t}+b_{13} \text { DangerA }_{i t} \\ +b_{14} \text { NotDangerB }_{i t}+b_{15} \text { PotatoConsumption }_{2, i t}+b_{16} \text { PotatoConsumption }_{3, i t} \\ +b_{17} \text { PotatoConsumption }_{4, i t}\end{array}\right)+e_{i t}+u_{i}$

Table 4 shows the coefficient estimates from the regression. Results show that consumers are indeed WTP a premium to exchange their agricultural endowment. Mean bid is 60 cents per kilo of potatoes. Bids are increasing across rounds. As expected subjects that perceived consumption of agricultural products from region B to pose no health risk, bid $0.43 €$ more to exchange their endowed products. Gender, income, households with underage kids and 
education do not seem to influence bidding behaviour in a statistically significant way. Consumption habits of potatoes also do not have an effect on bidding behaviour. Similarly, provision of extra information regarding the health risks of children was not statistically significant. Contrary to expectations, information effects are not evident in this experiment although commonly reported in the relevant literature. We contend that health risks for children are already considered when consumers state their value to hedge against health risks. This is an interesting avenue for future research as well.

Table 4: Econometric results

\begin{tabular}{|c|c|}
\hline Variable & $\begin{array}{c}\text { Coef. } \\
\text { (St Error) }\end{array}$ \\
\hline Constant & $\begin{array}{c}1.769 \\
(1.267)\end{array}$ \\
\hline Charity & $\begin{array}{l}-0.251 \\
(0.155)\end{array}$ \\
\hline HealthRisk & $\begin{array}{l}-0.208 \\
(0.148)\end{array}$ \\
\hline TotFee & $\begin{array}{l}-0.073 \\
(0.050)\end{array}$ \\
\hline$T_{2}$ & $\begin{array}{l}0.058^{*} \\
(0.033)\end{array}$ \\
\hline$T_{3}$ & $\begin{array}{c}0.149 * * * \\
(0.033)\end{array}$ \\
\hline$T_{4}$ & $\begin{array}{c}0.189 * * * \\
(0.033)\end{array}$ \\
\hline$T_{5}$ & $\begin{array}{c}0.236 * * * \\
(0.033)\end{array}$ \\
\hline Age & $\begin{array}{c}0.005 \\
(0.008)\end{array}$ \\
\hline Gender & $\begin{array}{l}-0.094 \\
(0.171)\end{array}$ \\
\hline Income $_{2}$ & $\begin{array}{c}0.235 \\
(0.146)\end{array}$ \\
\hline$E d u c_{2}$ & $\begin{array}{c}0.007 \\
(0.155)\end{array}$ \\
\hline Kids & $\begin{array}{l}-0.068 \\
(0.168)\end{array}$ \\
\hline DangerA & $\begin{array}{c}0.079 \\
(0.236)\end{array}$ \\
\hline NotDangerB & $\begin{array}{c}0.436 * * \\
(0.209)\end{array}$ \\
\hline PotatoConsumption. 2 & 0.392 \\
\hline
\end{tabular}


PotatoConsumption $_{3} \quad-0.170$

PotatoConsumption $_{4} \quad-0.004$

R-squared 0.278

\section{Conclusions and policy recommendations}

This chapter reports the results of an experimental auction designed to examine whether consumers are WTP a price premium to reduce the potential health risks associated with consumption of products that are cultivated in river basins that are not in a good ecological status. Health risks are a significant element of the environmental cost associated with water quality degradation and thus should be considered in the calculation of the total economic cost of water uses as the Directive requires.

To fulfil our research aims we endowed subjects with a kilo of potatoes cultivated in a river basin with characteristics similar to Asopos and gave them the opportunity to bid to exchange them with a kilo of similar variety potatoes from a river basin described as being in a good ecological status. Information on the advanced risks for children was also provided to half of our sample to assess the effect of information on valuation. Moreover, risks perceptions were also elicited at the end of the study and were accounted for in the analysis. Results of this study suggest that subjects are willing to pay more to upgrade from agricultural products cultivated in a polluted river basin products from areas in good ecological status. Mean upgrade bid is 60 cents per kilo of potatoes. This was so even though individuals were informed that epidemiological data that would allow assessment of the presence of risks for human health were not available. 
This represents an external cost to the farmers in the area limiting their opportunity to market their products. It is indicative that although every caution was taken to accurately present the situation regarding the health implications of the consumption of agricultural products from region $\mathrm{A}, 86 \%$ of the consumers perceived consumption of the products as being dangerous for their health. Economic instruments are thus in order, as the WFD requires, to compensate farmers for the income loss they bear if the analysis of water uses confirms that agriculture is not contributing to the ecological degradation. Polluters should then be identified and charged so that the total cost of water services, including external costs of ecosystem degradation, is recovered according to the polluter pays principle that the WFD introduces.

If on the other hand, epidemiological data fail to confirm causality between consumption of agricultural products from the Asopos $\mathrm{RB}$ and health risks, educational and information programs and campaigns should be developed so that consumers regain acceptance of the areas agricultural products. Past experience has shown that such campaigns are effective in diminishing consumers' resistance (Nayga, 1996).

\section{References}

Aldrich L., 1994. Food Safety Policy: Balancing Risk and Costs. Food Review, the magazine of food economics, May-August 1994, p. 9-13. U.S.D.A., Economic Research Service.

Commission of the European Communities (CEC) 2000. Directive of the European Parliament and of the Council establishing a framework for Community action in the field of water policy. 1997/0067 (COD), C5-0347/00. 
Costa-front, G., Gil, G.M., Traill, W.B., 2008. Consumer acceptance, valuation of and attitudes towards genetically modified food: Review and implications for food policy. Food Policy 33: 99-111.

Florax, R.J, Travisi, C., Nijkamp, P., 2005. A meta-analysis of the willingness to pay for reductions in pesticide risk exposure. European Review of Agricultural Economics 32: 441-467.

Frewer, LJ, Howard, C, Hedderley, D, Shepherd, R., 1998. Methodological approaches to assessing risk perceptions associated with food related hazards. Risk Analysis 18: 95-102.

Lusk, J.L., Jamal, M., Kurlander, L., Roucan, M., Taulman, L. 2005. A meta-analysis of genetically modified food valuation studies, Journal of Agricultural and Resource Economics 30:28-44.

Lusk, J.L. and Shogren, J.F., 2007. Experimental Auctions: Methods and Applications in Economic and Marketing Research, Cambridge University Press, UK.

Morkbak, M. R., Christensen, T., Gyrd-Hansen, D. 2008. Valuation of food safety in meat - a review of stated preference studies. Food Economics - Acta Agriculturae Scandinavica, Section C Vol. 5.

Rozan A., Stenger A. and Willinger M., 2004. Willingness-to-pay for food safety: an experimental investigation of quality certification on bidding behaviour. European Review of Agricultural Economics 31: 409-425.

Slovic, P., 1987. Perception of risk. Science 236(4799): 280-285.

Stenger, A., 2000. Experimental valuation of food safety, Application to Sewage Sludge. Food Policy 25:211-218. 


\section{Appendix I: Environmental Health Risk information}

\section{Environmental profile of region A}

Region A is characterized by intensive industrial activity, with many of the industries not fulfilling the safety standards, and intensive agricultural activity. Underground water analysis has revealed the presence of heavy metals, such as chromium and nickel, which may have contaminated plants through irrigation. The severity of these substances for human health depends on the degree and the duration of the exposure. However, an epidemiological study assessing accurately the risks for human health from the consumption of agricultural products from region $\mathrm{A}$, has not been performed yet. In addition, with respect to potatoes heavy metals tend to accumulate in the skin of potatoes and not in the interior that is commonly consumed.

\section{Environmental profile of region $B$}

Region B is classified as in good ecological status, according to the European Water Framework Directive. The good ecological status guarantees that pollution loads are minor such that there is no risk for human health and aquatic life. The agricultural sector follows good agricultural and environmental practices and there is no industrial activity in the area. Measurements in potatoes from the area revealed that the accumulation in heavy metals is far below the international safety levels.

\section{Information on the advanced risks for children}


Children are extremely vulnerable to toxic substances in agricultural products. Children have a longer life spam compared to adults and therefore are more likely to experience long-term effects from heavy metal contamination since exposure is cumulative. 